\title{
Bulk crystal growth and characterization of ZnSnP 2 compound semiconductor by flux method
}

\section{$\operatorname{AUTHOR}(S)$ :}

Nakatsuka, Shigeru; Nakamoto, Hiroshi; Nose, Yoshitaro; Uda, Tetsuya; Shirai, Yasuharu

\section{CITATION:}

Nakatsuka, Shigeru ...[et al]. Bulk crystal growth and characterization of ZnSnP 2 compound semiconductor by flux method. physica status solidi (c) 2015, 12(6): 520-523

\section{ISSUE DATE: \\ 2015-03-30}

URL:

http://hdl.handle.net/2433/201961

\section{RIGHT:}

This is the peer reviewed version of the following article: Nakatsuka, S., Nakamoto, H., Nose, Y., Uda, T. and Shirai, Y. (2015), Bulk crystal growth and characterization of ZnSnP2 compound semiconductor by flux method. Phys. Status Solidi C, 12: 520-523, which has been published in final form at http://dx.doi.org/10.1002/pssc.201400291. This article may be used for non-commercial purposes in accordance with Wiley Terms and Conditions for Self-Archiving.; The fulltext file will be made open to the public on 30 March 2016 in accordance with publisher's 'Terms and Conditions for Self-Archiving':; This is not the published version. Please cite only the published version.; この論文は出版社版でありま せん。引用の際には出版社版をご確認ご利用ください。 


\title{
Bulk crystal growth and characteriza- tion of $\mathrm{ZnSnP}_{2}$ compound semicon- ductor by flux method
}

\author{
Shigeru Nakatsuka ${ }^{1}$, Hiroshi Nakamoto ${ }^{1}$, Yoshitaro Nose ${ }^{*, 1,2}$, Tetsuya Uda $^{1}$ and Yasuharu Shirai $^{1}$ \\ ${ }^{1}$ Department of Materials Science and Engineering, Kyoto University, Kyoto 606-8501, Japan \\ 2 JST-PRESTO, Japan
}

Received ZZZ, revised ZZZ, accepted ZZZ

Published online ZZZ (Dates will be provided by the publisher.)

Keywords. Chalcopyrite, Crystal growth, Flux method, Order-disorder

\begin{abstract}
$\mathrm{ZnSnP}_{2}$ is a promising candidate for solar absorber materials from the viewpoint of high absorption and earthabundant constitution elements. In this paper, we fabricated $\mathrm{ZnSnP}_{2}$ crystals by flux method based on the phase diagram of $\mathrm{Sn}-\mathrm{ZnP}_{2}$ pseudo-binary system and investigated their properties for an application to photovoltaics. The crystal growth experiments with the cooling rate of 0.7 and $12{ }^{\circ} \mathrm{C} / \mathrm{h}$ were carried out and we successfully obtained $\mathrm{ZnSnP}_{2}$ crystals with the diameter of $8 \mathrm{~mm}$ and the thickness of a few mm by a slow cooling rate. The structure of grown crystals studied by $\mathrm{X}$-ray diffraction was indicated to be chalcopyrite-type $\mathrm{ZnSnP}_{2}$. In addition, the
\end{abstract}

\begin{abstract}
decrease of the degree of order was observed with the increase of cooling rate. The lattice constants of a and c axes are 5.649 and $11.295 \AA$, respectively. The composition of grown crystals is a near stoichiometric ratio of $\mathrm{ZnSnP}_{2}$ by EDX analysis. The bandgaps of $\mathrm{ZnSnP}_{2}$ crystals obtained by cooling rate of 0.7 and $12{ }^{\circ} \mathrm{C} / \mathrm{h}$ were estimated to be 1.61 and $1.48 \mathrm{eV}$, respectively, which is caused by the difference of the degree of order. The hall-resistivity measurement showed that $\mathrm{ZnSnP}_{2}$ crystals with a slow cooling rate has a p-type conduction. The resistivity, the hole concentration and the mobility are $10 \sim 70 \Omega \mathrm{cm}, 6 \cdot 10^{16} \sim 2 \cdot 10^{17}$ $\mathrm{cm}^{-3}$, and $1 \sim 3 \mathrm{~cm}^{2} \mathrm{~V}^{-1} \mathrm{~s}^{-1}$. The obtained properties are suitable for an absorber of photovoltaics.
\end{abstract}

Copyright line will be provided by the publisher
1 Introduction Recently, photovoltaic devices using various type of materials have been investigated for the increasing energy demand and low-cost. Above all, solar cells using CdTe with II-IV type semiconductor and $\mathrm{Cu}(\mathrm{In}, \mathrm{Ga}) \mathrm{Se}_{2}$ (CIGS) with chalcopyrite-type structure have high efficiencies, $20.4 \%$ and $20.8 \%$, respectively [1]. Although the above solar cells are in practical use in late years, it is not desirable to use toxic elements, $\mathrm{Cd}$ and Te, and minor elements, In and Ga. On these backgrounds, solar absorbing materials consisting of earth-abundant and lowtoxic elements have been researched and solar cells using $\mathrm{Cu}_{2} \mathrm{ZnSnS}_{4-\mathrm{x}} \mathrm{Se}_{\mathrm{x}}$ achieved a conversion efficiency of $12.6 \%$ [2], which is insufficient compared to CIGS.

In this work, we thus concentrated on a ternary compound semiconductor $\mathrm{ZnSnP}_{2}$ with chalcopyrite structure as a new solar absorber. This compound also consists of earth-abundant and low-toxic elements. It was also reported that $\mathrm{ZnSnP}_{2}$ thin films fabricated by coevaporation had a p-type conduction, a direct bandgap of $1.62 \mathrm{eV}$ and a high absorption coefficient $\left(\alpha>10^{5} \mathrm{~cm}^{-1}\right)$ in visible light range [3]. Therefore, $\mathrm{ZnSnP}_{2}$ is a promising material for a solar absorbing layer in photovoltaic devices. For the investigation of $\mathrm{ZnSnP}_{2}$ properties, several studies on crystal growth by flux method using Sn solution were reported [4-10]. In these reports, it was shown that $\mathrm{ZnSnP}_{2}$ crystals with chalcopyrite or sphalerite structures were obtained depending the cooling rate during crystal growth. The change of the crystal structure is attributed to the orderdisorder transition, where the ordered and the disordered phases are chalcopyrite and sphalerite phases, respectively [11]. In the disordered phase, $\mathrm{Zn}$ and Sn atoms ramdomly occupy on their sites. The reported properties of $\mathrm{ZnSnP}_{2}$ are summarized in Table 1 . The bandgap of $\mathrm{ZnSnP}_{2}$ with sphalerite structure is in the range of 1.22 to $1.32 \mathrm{eV}$, while that of chalcopyrite phase is significantly different from literatures: 1.2 to $1.67 \mathrm{eV}$. In the reported works, $\mathrm{ZnSnP}_{2}$ with chalcopyrite structure was obtained with the cooling rate of 5 or $10{ }^{\circ} \mathrm{C} / \mathrm{h}$, which is relatively rapid in the viewpoint of crystal growth. This rapid cooling rates led to the precipitation of $\mathrm{ZnSnP}_{2}$ crystals in the form of plates with the small dimensions of about $4 \times 4 \times 0.3 \mathrm{~mm}$ [5]. In addition, it is considered that one of the reasons for wide

* Corresponding author: e-mail nose.yoshitaro.5e@kyoto-u.ac.jp, Phone: +81-75-753-5472, Fax: +81-75-753-3579 
range of reported bandgaps is the intermediate structure between chalcopyrite and sphalerite, which is a partlydisordred state.

In this report, we thus aimed to fabricate $\mathrm{ZnSnP}_{2}$ crystals with a larger size to be available for various evaluations and investigate the effect of cooling rate on their properties. Figure 1 shows the phase diagram of the $\mathrm{Sn}-\mathrm{ZnP}_{2}$ pseudobinary system established by our previous work [12]. In the crystal growth of $\mathrm{ZnSnP}_{2}$, it is difficult to obtain crystals with a single-phase from congruent solidification because the peritectic reaction between $\mathrm{ZnP}_{2}$ and liquid $\mathrm{Sn}$ is observed. Therefore, it is understood that the usage of Sn solution with the composition of more than $90 \mathrm{~mol} \% \mathrm{Sn}$ is necessary for $\mathrm{ZnSnP}_{2}$ crystal growth.

Table 1 Properties of $\mathrm{ZnSnP}_{2}$ crystals grown by flux method.

\begin{tabular}{|c|c|c|c|c|c|}
\hline Phase & $\begin{array}{l}\text { Cooling } \\
\text { rate } \\
/{ }^{\circ} \mathrm{Ch}^{-1}\end{array}$ & $\begin{array}{c}\text { Bandgap } \\
\text { / eV }\end{array}$ & $\begin{array}{c}\text { Hole } \\
\text { concentration } \\
/ \mathrm{cm}^{-3}\end{array}$ & $\begin{array}{c}\text { Mobility } \\
/ \mathrm{cm}^{2} \mathrm{~V}^{-1} \mathrm{sec}^{-1}\end{array}$ & Ref. \\
\hline \multirow{8}{*}{ Chalcopyrite } & 5 & & $7.3 \cdot 10^{16}$ & 68 & [4] \\
\hline & 10 & 1.2 & & 30 & [5] \\
\hline & & & $(5.0 \sim 7.3) \cdot 10^{16}$ & $48 \sim 68$ & [6] \\
\hline & 5 & 1.46 & & & [7] \\
\hline & & 1.45 & $(3 \sim 5) \cdot 10^{16}$ & 50 60 & [8] \\
\hline & & 1.67 & $(1.2 \sim 1.6) \cdot 10^{18}$ & $5 \sim 10$ & [9] \\
\hline & 5 & 1.64 & & & [10] \\
\hline & 0.7 & 1.61 & $\begin{array}{c}6 \cdot 10^{16} \\
\sim 2 \cdot 10^{17}\end{array}$ & $1 \sim 3$ & * \\
\hline \multirow{5}{*}{$\begin{array}{l}\text { Partly } \\
\text { disorder }\end{array}$} & 25 & & $6.8 \cdot 10^{16}$ & 24 & [4] \\
\hline & 50 & & $7.2 \cdot 10^{16}$ & 9.3 & [4] \\
\hline & 75 & & $6.6 \cdot 10^{16}$ & 8 & [4] \\
\hline & 1200 & & $8.8 \cdot 10^{16}$ & 4.5 & [4] \\
\hline & 12 & 1.48 & & & $*$ \\
\hline \multirow{4}{*}{ Sphalerite } & & & $\begin{array}{c}7.2 \cdot 10^{16} \\
\sim 1.8 \cdot 10^{17}\end{array}$ & 6.3 7.6 & [6] \\
\hline & 75 & 1.22 & & & [7] \\
\hline & & 1.32 & $(1 \sim 2) \cdot 10^{16}$ & $6 \sim 10$ & [8] \\
\hline & 13 & 1.25 & & & [10] \\
\hline
\end{tabular}

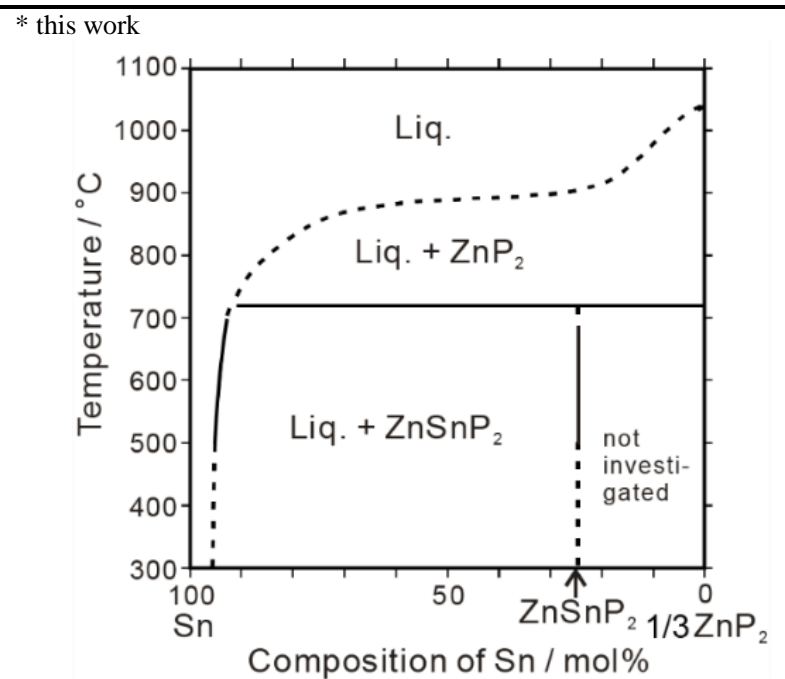

Figure 1 Phase diagram of $\mathrm{Zn}-\mathrm{SnP}_{2}$ pseudo binary system [12].
2 Experimental procedure Raw materials, Zn shots (99.9999\%, Kojundo Kagaku), Sn shots (99.99\%, Kojundo Kagaku) and red phosphorus flacks (99.9999\%, Kojundo Kagaku) were sealed in evacuated quartz ampule with the inner diameter of 6 or $10 \mathrm{~mm}$ under the pressure below $10^{-2}$ $\mathrm{Pa}$. Zn and Sn were chemical-etched using $0.1 \mathrm{M} \mathrm{HCl}$ solution before sealed in the ampule. The nominal composition was controlled to be $92 \mathrm{~mol} \% \mathrm{Sn}$ determined by the phase diagram of $\mathrm{Sn}-\mathrm{ZnP}_{2}$ system shown in Fig. 1. Then, the quartz ampule was set in the growth furnaces shown in Fig. 2 , which has three heaters to control temperature gradient precisely. The sealed ampule was located at the position around $700{ }^{\circ} \mathrm{C}$ for homogenization. After that, the furnaces were lifted up by the rate of 0.2 or $3.5 \mathrm{~mm} / \mathrm{h}$ and the sample was unidirectionally solidified from the bottom. The temperature of the bottom of the ampule was monitored by Ktype thermocouple during crystal growth. After the growth experiments, bulk crystals obtained by the rate of $0.2 \mathrm{~mm} / \mathrm{h}$ were cut into several wafers in the direction perpendicular to the growth direction. The surface of each wafer was mechanically polished with a series of emery papers and finally with $1 \mu \mathrm{m}$ diamond slurry on a buff sheet. Some grown crystals were ground into a fine powder by mortar and pestle. On the other hand, crystals by the rate of $3.5 \mathrm{~mm} / \mathrm{h}$ were extracted from the sample by dissolving $\mathrm{Sn}$ in $0.1 \mathrm{M} \mathrm{HCl}$ solution and formed into powder. The product phase was identified by X-ray diffraction (XRD, Panalytical X'Pert Pro) and the composition of the crystals was analysed by SEM (KEYENCE VE-7800) and EDX (EDAX VE-9800). The lattice constant was evaluated from XRD profiles of powder specimens by Rietveld analysis using a software $X$ 'Pert HighScore Plus. The bandgap was estimated by diffuse reflectance spectra of powder specimens using Spectrophotometer (HITACHI U-3500). The Hall effect and the resistivity measurements were carried out at room temperature based on van der Pauw method by Hall-Resistivity measurement system (Toyo Technica, ResiTest 8300) and the density and the mobility of carrier were evaluated.

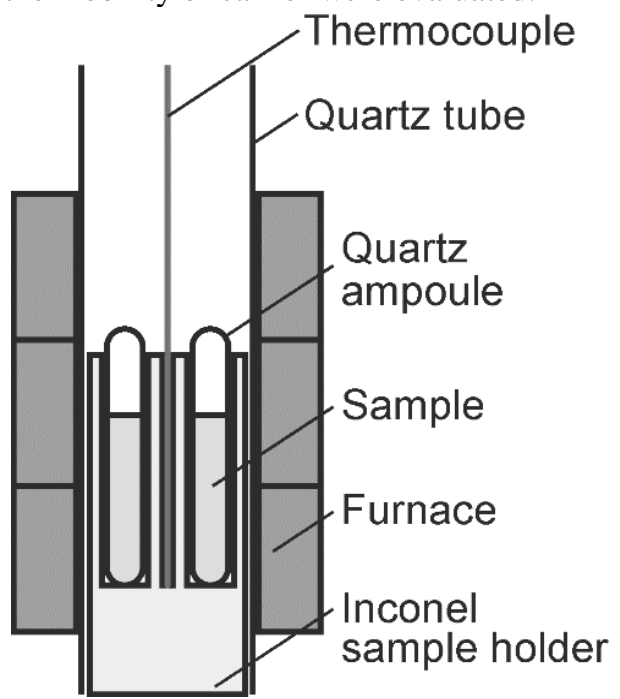

Figure 2 Schematic illustration of furnace for crystal growth. 


\section{Results and discussion}

\section{3-1. Dependence of cooling rate on precipitation behavior}

Figure 3 shows the photographs of samples after crystal growth by the furnace lifting with 0.2 and $3.5 \mathrm{~mm} / \mathrm{h}$, which correspond to a cooling rate of 0.7 and $12{ }^{\circ} \mathrm{C} / \mathrm{h}$, respectively. In the sample obtained by the slow cooling rate, the precipitation of $\mathrm{ZnSnP}_{2}$ crystal was observed at the bottom of the sample as shown in Fig. 3(a). The obtained crystal was a polycrystal with a diameter of $8 \mathrm{~mm}$ and a length of $10 \mathrm{~mm}$ which was larger compared to reported works. The grain size was about $1 \mathrm{~mm}$ as shown in Fig. 3(c). On the other hand, the rapid cooling rate led to a dispersed precipitation of small crystals shown in Fig. 3(b). In general, a supersatuation of solute is necessary for a precipitation of crystal from solution. In this study, it is needed that $\mathrm{Zn}$ and $\mathrm{P}$ diffuse to the interface between the crystal and the solution until enough supersaturation for crystal growth. The diffusion coefficient of $\mathrm{Zn}$ in liquid $\mathrm{Sn}$ at $700{ }^{\circ} \mathrm{C}$ is calculated to be about $5 \times 10^{-5} \mathrm{~cm}^{2} \mathrm{sec}^{-1}$ [13]. The mean diffusion length of $\mathrm{Zn}$ is evaluated to be $4 \mathrm{~mm} / \mathrm{h}$ using $\sqrt{D t}$. The slow lifting speed of $0.2 \mathrm{~mm} / \mathrm{h}$ leads to an enough time for diffusion of $\mathrm{Zn}$ to the bottom of the sample and the precipitation can occur at the bottom. In contrast, the solidification of the solution occurred before the solute was supersaturated at the bottom in the case of the lifting speed of $3.5 \mathrm{~mm} / \mathrm{h}$ because the velocity of both solidification and diffusion of $\mathrm{Zn}$ in solution are comparable. Consequently, the dispersed precipitations of $\mathrm{ZnSnP}{ }_{2}$ were observed in the sample by the rapid cooling rate.

\section{3-2. Investigation on some properties}

Figure 4 shows the powder XRD profiles of the grown crystals, which indicate that the grown crystals are $\mathrm{ZnSnP}_{2}$ with a single phase. Here, the intensity of superlattice reflection in the crystals decrease with the increase of the cooling rate. The degree of order was evaluated using the ratio of integrated intensities of (101) and (112) peaks, which are superlattice and fundamental reflections, respectively [14]. In this work, the ratio decreases from 0.076
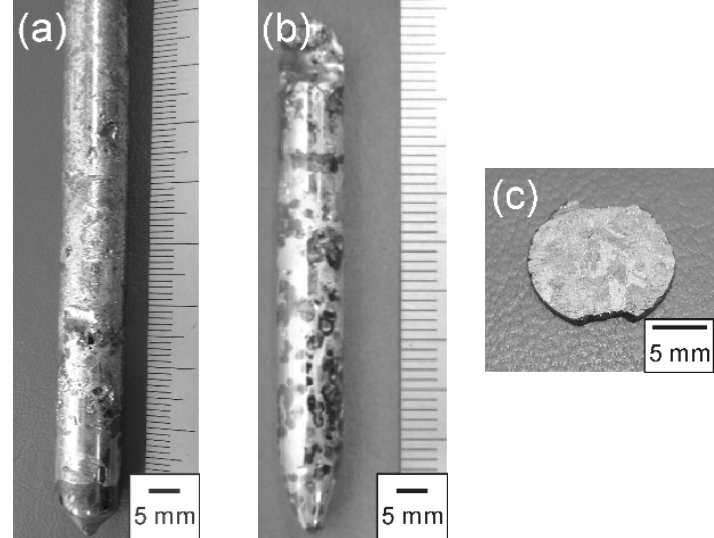

Figure 3 Photographs of samples after crystal growth with the cooling rate of (a) 0.7 and (b) $12^{\circ} \mathrm{C} / \mathrm{h}$, and (c) a wafer of grown crystal with the rate of $0.7^{\circ} \mathrm{C} / \mathrm{h}$. to 0.057 with increasing cooling rate, which means the decrease of the degree of order. The reported works also show a similar trend $[4,6-8,10]$. Consequently, the lattice constants of a and c axes were evaluated to be 5.649 and $11.295 \AA$, respectively, using the XRD profiles of the crystal obtained by the slow cooling rate. The ratio c/a is 2 . The composition of the samples was an almost stoichiometric ratio of $\mathrm{ZnSnP}_{2}$, which was analysed by EDX.

In order to evaluate bandgaps of the crystals, the diffuse reflectance, $R$, is convert to Kubelka-Munk function, $F(R)$, which represents the light absorption as expressed in equation (1) [15],

$$
F(R)=\frac{(1-R)^{2}}{2 R}=\frac{\alpha}{S},
$$

where $\alpha$ and $S$ are the absorption and the scattering coefficients, respectively. In the case of a direct transition, the absorption coefficient is correlated to photon energy by Tauc's equation,

$$
\alpha=\frac{A\left(E-E_{g}\right)^{1 / 2}}{E},
$$

where $E$ and $A$ are photon energy and a constant which depends on properties of materials. Consequently, the energy bandgap, $E_{g}$, is evaluated by Tauc's plot of the Kubelka-Munk function based on equation (3) [16].

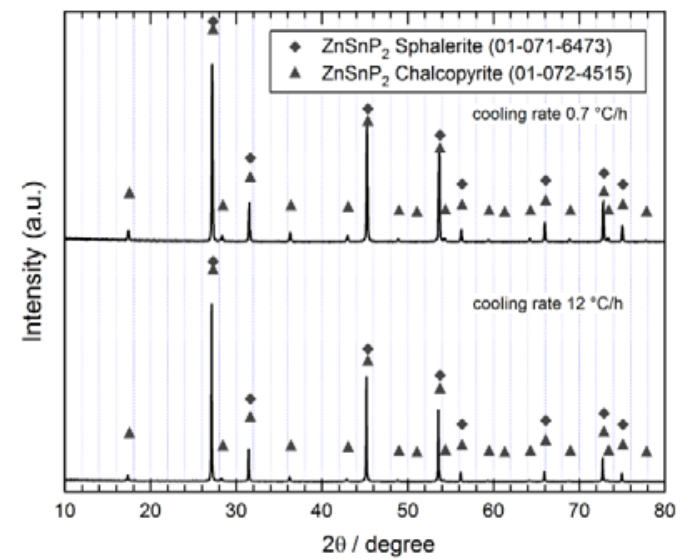

Figure 4 Powder XRD profiles of grown crystals.

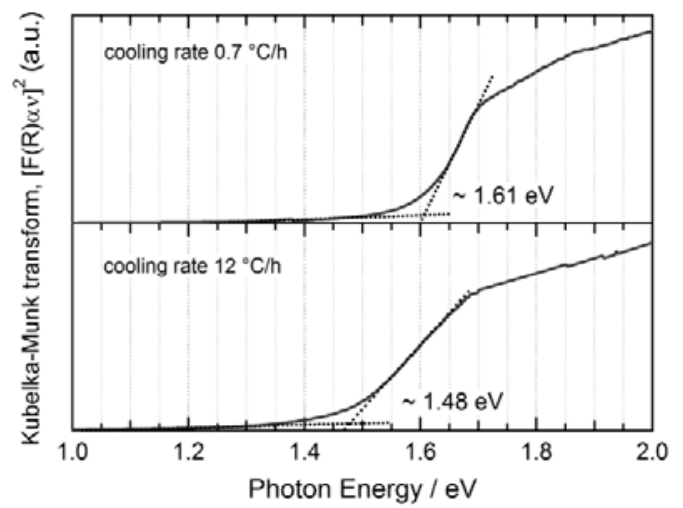

Figure 5 Tauc's plot of Kubelka-Munk transform using the diffuse reflectance measurements of powder samples. 


$$
[F(R) E]^{2}=\left(\frac{\alpha E}{S}\right)^{2}=\left(\frac{A}{S}\right)^{2}\left(E-E_{g}\right) .
$$

The bandgaps of $\mathrm{ZnSnP}_{2}$ crystals prepared by the cooling rate of 0.7 and $12{ }^{\circ} \mathrm{C} / \mathrm{h}$ were estimated to be about 1.61 and $1.48 \mathrm{eV}$, respectively, as shown in Fig. 5. The former is close to the value reported by Ryan et al. [5]. In addition, they also reported that bandgap of $\mathrm{ZnSnP}_{2}$ with sphalerite structure is $1.25 \mathrm{eV}$, while Rubenstein et al. reported the bandgap of $\mathrm{ZnSnP}_{2}$ with chalcopyrite is $1.2 \mathrm{eV}$. In this case, the structure of $\mathrm{ZnSnP}_{2}$ might be close to sphalerite. Moreover, Berkovskii et al. [7] and Goryunova et al. [8] reported the bandgap of chalcopyrite is 1.46 and $1.45 \mathrm{eV}$, respectively, which are close to the value of the $\mathrm{ZnSnP}_{2}$ crystal obtained by the cooling rate of $12^{\circ} \mathrm{C} / \mathrm{h}$ in this work. Therefore, their reported crystals are also considered to be an intermediate state between chalcopyrite and sphalerite structure, which is a partly-disordered state.

The electric properties of $\mathrm{ZnSnP}_{2}$ crystals with the cooling rate of $0.7^{\circ} \mathrm{C} / \mathrm{h}$ were evaluated using the Hall and resistivity measurements. The crystals obtained by the cooling rate of $12^{\circ} \mathrm{C} / \mathrm{h}$ was too small to evaluate the electric properties. The Hall effect measurement indicates that $\mathrm{ZnSnP}{ }_{2}$ prepared in this work shows a p-type conduction. The resistivity, the hole concentration and the mobility are

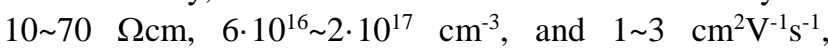
respectively. The hole concentration of the crystal in this work is close to that in reported works, which is suitable for solar cell devices. On the other hand, the mobility is about one order of magnitude smaller than the literature data. It is likely that the difference of the mobility is attributed to the cooling rate, however, further investigation is necessary to clarify.

4 Conclusions In this paper, $\mathrm{ZnSnP}_{2}$ crystal growth was carried out by flux method with the cooling rate of 0.7 and $12{ }^{\circ} \mathrm{C} / \mathrm{h}$. The, polycrystals with the diameter of $8 \mathrm{~mm}$ and the thickness of a few $\mathrm{mm}$ were obtained with the slow cooling rate, while the rapid cooling rate led to the dispersed precipitation of small crystals. The precipitation behaviours can be understood based on the diffusion of $\mathrm{Zn}$ in liquid $\mathrm{Sn}$. The precipitated crystals with the cooling rate of 0.7 and $12{ }^{\circ} \mathrm{C} / \mathrm{h}$ were identified as $\mathrm{ZnSnP}_{2}$ by $\mathrm{XRD}$, however the decrease of the degree of order evaluated from XRD proriles was observed with increasing cooling rate. The bandgaps of $\mathrm{ZnSnP}{ }_{2}$ with the cooling rate of 0.7 and $12^{\circ} \mathrm{C} / \mathrm{h}$ were calculated to be 1.61 and $1.48 \mathrm{eV}$ using diffuse reflectance spectra, which was due to the difference of the degree of order. The hall-resistivity measurement showed that $\mathrm{ZnSnP}_{2}$ crystals with slow cooling rate have a p-type conduction, and the electric properties suggest that $\mathrm{ZnSnP}_{2}$ with chalcopyrite structure is suitable for a solar absorbing material.
Acknowledgements The authors thanks to Dr. H. Hayashi for his support on hall-resistivity measurements. This work was partly supported by JSPS KAKENHI Grant Number 21760599, and Elements Science and Technology project from MEXT, Japan, and PRESTO from Japan Science and Technology Agency.

\section{References}

[1] M. A. Green, K. Emery, Y. HIshikawa, W. Warta and E. D. Dunlop, Prog. Photovolt: Res. Appl. 22, 1 (2013).

[2] W. Wang, M. T. Winkler, O. Gunawan, T. Gokmen, T. K. Todorov, Y. Zhu and D. B. Mitzi, Adv. Energy Mater., doi: 10.1002/aenm.201301465 (2013).

[3] H. Y. Shin and P. K. Ajmera, Mater. Lett. 5, 211 (1987).

[4] A. A. Vaipolin, N. A. Goryunova, L. I. KleShohinskii, G. V. Loshakova and E. O. Osmanov, Phys. Stat. Sol. 29, 435 (1968).

[5] M. Rubenstein and R. W. Ure, J. Phys. Chem. Solids, 29, 551 (1968).

[6] N. A. Goryunova, F. P. Kesamanly and G. V. Loshakova, Sov. Phys. Semicond., 1, 844 (1968).

[7] F. M. Berkovskii, D. Z. Garbuzov, N. A. Goryunova, G. V. Loshakova, S. M. Ryvkin and G. P. Shpen'kov, Sov. Phys. Semicond., 2, 618 (1968).

[8] N. A. Goryunova, M. L. Belle, L. B. Zlatkin, G. V. Loshakova, A. S. Poplavnoi and V. A. Chaldyshev, Sov. Phys. Semicond., 2, 1126 (1969).

[9] A. A. Abdurakhimov, L. V. Kradinova, Z. A. Parimbekov and Yu. V. Rud', Sov. Phys. Semicond. 16, 156 (1982).

[10] M. A. Ryan, M. W. Peterson, D. L. Willliamson, J. S. Frey, G. E. Maciel and B. A. Parkinson, 2, 528 (1987).

[11] G. A. Seryogin, S. A. Nikishin, H. Temkin, A. M. Mintairov, J. L. Merz and M. Holtz, Appl. Phys. Lett., 74, 2128 (1999).

[12] Y. Nose and T. Uda, Technical Digest of 21 st. International Photovoltaic Science and Engineering Conference, 2D-3P35 (2011).

[13] C. H. Ma and R. A. Swalin, Acta. Met., 8, 388 (1960).

[14] B. E. Warren, X-ray diffraction (Addison-Wesley, Boston, 1969).

[15] H. Lin, C. P. Huang, W. Li, C. Ni, S. I. Shah and Y. H. Tseng, Appl. Catal. B: Environ., 68, 1 (2006).

[16] J. Tauc, R. Grigorovici and A. Vancu, Phys. Satatus Solidi, 15, 627 (1966). 